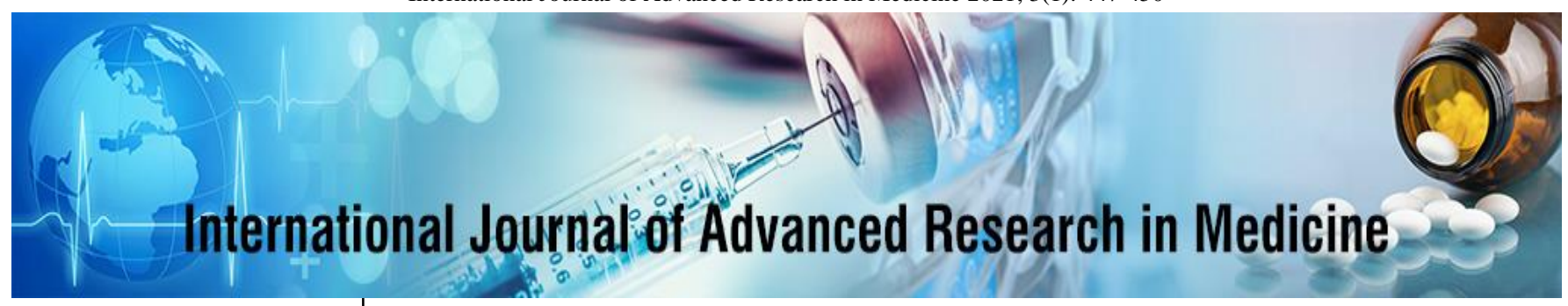

E-ISSN: 2706-9575 P-ISSN: 2706-9567 IJARM 2021; 3(1): 447-450 Received: 01-01-2021 Accepted: 03-03-2021

Dr. Samina Tarannum M.D. (Gen Med), Associate Professor, Department of General Medicine, Osmania Medical College, Hyderabad, Telangana, India
Corresponding Author: Dr. Samina Tarannum M.D. (Gen Med), Associate Professor, Department of General Medicine, Osmania Medical College, Hyderabad, Telangana, India

\section{Comparison of fasting and post prandial lipid profile in patients of IHD}

\section{Dr. Samina Tarannum}

DOI: $\underline{\text { https://doi.org/10.22271/27069567.2021.v3.i1h.178 }}$

\begin{abstract}
Background: Despite recent advancements in medical services and treatment regimens, ischemic heart disease (IHD) is still the leading cause of death in both developed and developing countries. While hypercholesterolemia and hypertriglyceridemia are considered separate risk factors, most recent research in this area have focused at fasting lipids and lipoproteins.

Aims and Objectives: To compare the fasting and post prandial lipid profile in patients of IHD.

Materials and Method: Upon receiving informed consent, 50 patients with IHD who were reporting to the Department of Medicine were enrolled in the current study. A previous history of myocardial infarction, ECG data, echocardiography, coronary artery bypass grafting surgery, or a coronary angiogram is used to diagnose CHD. For at least six months prior to the study, all of these patients had been free of some clinical incident. Both of the enrolled patients were given a thorough clinical review, with the results being entered into a prestructured proforma. After a twelve-hour overnight fast and two hours after a mixed diet, each subject's venous blood was obtained aseptically. Fasting samples and postprandial (PP) samples were analyzed for lipid profile and blood sugar; blood sugar was measured in 2 hour PP samples and lipids in 4 hour PP samples.

Results: Tobacco chewing (30\%) was the most common risk factor observed followed by smoking and hypertension $(20 \%)$. It was observed that mean fasting sugar level of the study subjects was $85.40 \pm 21.25 \mathrm{mg} / \mathrm{dl}$ while post prandial sugar level was $112.60 \pm 24.50 \mathrm{mg} / \mathrm{dl}$. It was observed that mean fasting triglycerides was $210.02 \pm 63.9 \mathrm{mg} / \mathrm{dl}$ and mean post prandial triglycerides $275.65 \pm 48.0 \mathrm{mg} / \mathrm{dl}$ and the difference was statistically significant. Fall in post prandial total cholesterol $(229.72 \pm 53.9 \mathrm{mg} / \mathrm{dl})$ was observed as compared to fasting level $(245.87 \pm 64.5 \mathrm{mg} / \mathrm{dl})$ but the difference observed was not statistically significant. Mean fasting HDL was $42.71 \pm 4.9 \mathrm{mg} / \mathrm{dl}$ while mean post prandial HDL was $40.65 \pm 3.6 \mathrm{mg} / \mathrm{dl}$. It was seen that mean fasting LDL was $156.45 \pm 23.9 \mathrm{mg} / \mathrm{dl}$ and mean post prandial LDL was $145.76 \pm 31.5 \mathrm{mg} / \mathrm{dl}$. It was observed that post prandial VLDL levels (41.76 \pm 28.55$)$ were raised as compared to fasting VLDL levels (37.90 \pm 17.6$)$ but the difference was not statistically significant.
\end{abstract}

Conclusion: Except for TG, which was statistically significant higher post-prandially, there was no significant clinical disparity between fasting and nonfasting levels of total cholesterol, HDL, or LDL.

Keywords: IHD, lipid profile, fasting, post prandial, PP

\section{Introduction}

Ischemic heart disease (IHD) is a syndrome in which a part of the myocardium absorbs insufficient blood and oxygen; it normally happens when myocardial oxygen supply and demand are out of proportion ${ }^{[1]}$.

Ischemic heart disease (IHD) is a leading cause of death in the Western world, and its prevalence is increasing in the United States. Diabetes, smoking history, asthma, obesity, a family history of IHD, and hyperlipidemia are among the most important risk factors in people with IHD. New risk factors for IHD have emerged in recent years, including the prevalence of inflammation as shown by elevated highly susceptible C-reactive arthritis (RA), Antiphospholipid antibody syndrome, and systemic lupus erythematosus, both of which have a significantly increased risk of developing IHD $^{[2]}$.

Fasting stage occurs after 8 hours of fast. ${ }^{3}$ Thus, most humans find themselves in the nonfasting state for the majority of a 24-hour period, perhaps with the exception of the early morning hours. Despite this fact, plasma lipids, lipoproteins, and apolipoproteins for cardiovascular risk prediction are usually measured in the fasting state ${ }^{[3-5]}$. A main reason is the increase in triglyceride levels seen during a fat tolerance test, in which patients typically consume $1 \mathrm{~g}$ fat per $1 \mathrm{~kg}$ body weight ${ }^{[6,7]}$. 
However, levels of nonfasting triglycerides are better at predicting future cardiovascular events than levels of fasting triglycerides ${ }^{[8,9]}$. Furthermore, it is possible that nonfasting levels of lipids, lipoproteins, and apolipoproteins differ only minimally from levels in the fasting state simply because most people consume far less fat at ordinary meals than during a fat tolerance test. Hypercholesterolemia and hypertriglyceridemia are considered the independent risk factors but most of the earlier studies in this area have considered only the fasting lipids and lipoproteins. Recently it has been proposed that postprandial lipoproteins may be better indicators of deranged lipoprotein metabolism and hence of atherosclerosis and CHD [10]. Postprandial hypertriglyceridemia (PHTG) and delayed triglyceride (TG) rich lipoprotein clearance have been found to impair endothelial function significantly either directly or by increasing superoxide anions. Since these lipoproteins are high in cholesterol and triglycerides, they can cause cholesterol-laden foam cells to shape when they are taken up by macrophages. The severity and extent of postprandial lipidaemia has also been linked to the pathogenesis and development of coronary heart disease $[11,12,13,14]$. As a result, the aim of this study was to determine the function of postprandial lipid profile as an indicator of lipoprotein metabolism efficiency and its relationship to the production of IHD.

\section{Materials and Methods}

With the aim to study and compare the fasting and post prandial lipid profile in patients of IHD. For the purpose of study 50 patients of IHD reporting to the study institute were enrolled in the study after taking informed consent. The diagnosis of CHD was based on previous history of myocardial infarction, ECG evidence, echocardiography, coronary artery bypass grafting surgery or coronary angiogram. All these patients were free of any clinical event for a period of at least six months prior to the study.

Many of the patients who were admitted underwent a thorough clinical review, with the results being entered into a pre-structured proforma. After a twelve-hour overnight fast and two hours after a mixed diet, each subject's venous blood was obtained aseptically.

In addition, routine investigations like haematological profile, blood urea, serum electrolytes, etc were also carried out in fasting samples of all the subjects. Total cholesterol (TC), HDL- cholesterol (HDL-C) and TG, VLDL and LDL were done

Statistical Analysis: The collected data was entered in Microsoft excel and was anazlyed and presented with appropriate tables and graphs.

\section{Observation and Results}

Table 1: Distribution of patients according to gender

\begin{tabular}{|c|c|c|}
\hline Gender & No. of patients & Percentage \\
\hline Male & 32 & $64 \%$ \\
\hline Female & 18 & $36 \%$ \\
\hline Total & 30 & 100 \\
\hline
\end{tabular}

It was observed that in the present study total $64 \%$ patients were male and $36 \%$ were female with male: female ratio of 1.73:1.
Table 2: Distribution of patients according to risk factors

\begin{tabular}{|c|c|c|}
\hline Risk factors $*$ & No. of patients & Percentage \\
\hline Smoking & 10 & $20 \%$ \\
\hline Diabetes mellitus & 10 & $20 \%$ \\
\hline Hypertension & 10 & $20 \%$ \\
\hline Tobacco chewing & 15 & $30 \%$ \\
\hline Family history of PCAD & 5 & $10 \%$ \\
\hline
\end{tabular}

While studying various risk factors of IHD in the study population it was observed that tobacco chewing (30\%) was the most common risk factor observed followed by smoking (20\%) and hypertension (20\%).

Table 3: Distribution of patients according to Biochemical parameter

\begin{tabular}{|c|c|c|}
\hline Biochemical parameter & Mean & Percentage \\
\hline Blood sugar $(\mathrm{F})$ & 85.40 & $21 \%$ \\
\hline Blood sugar $(\mathrm{PP})$ & 112.60 & $25 \%$ \\
\hline Blood urea $(\mathrm{mg} / \mathrm{dl})$ & 21.80 & $3 \%$ \\
\hline Serum sodium & 141.70 & $4 \%$ \\
\hline Serum potassium & 4.20 & $1 \%$ \\
\hline
\end{tabular}

It was observed that mean fasting sugar level of the study subjects was $85.40 \pm 21.25 \mathrm{mg} / \mathrm{dl}$ while post prandial sugar level was $112.60 \pm 24.50 \mathrm{mg} / \mathrm{dl}$. Mean blood urea, serum sodium and potassium was $21.80 \pm 2.90 \mathrm{mg} / \mathrm{dl}$, $141.70 \pm 4.40 \mathrm{meq} / \mathrm{l}$ and $4.20 \pm 1.20 \mathrm{meq} / \mathrm{l}$ respectively.

Table 4: Distribution of patients according to fasting and postprandial lipid profile

\begin{tabular}{|c|c|c|c|}
\hline Parameter & Fasting & Postprandial & Statistical significance \\
\hline Triglycerides & $210.02 \pm 63.9$ & $275.65 \pm 48.0$ & Significant \\
\hline Total cholesterol $245.87 \pm 64.5$ & $229.72 \pm 53.9$ & Not Significant \\
\hline HDL & $42.71 \pm 4.9$ & $40.65 \pm 3.6$ & Not Significant \\
\hline LDL & $156.45 \pm 23.9$ & $145.76 \pm 31.5$ & Not Significant \\
\hline VLDL & $37.90 \pm 17.6$ & $41.76 \pm 28.55$ & Not Significant \\
\hline
\end{tabular}

It was observed that mean fasting triglycerides was $210.02 \pm 63.9 \mathrm{mg} / \mathrm{dl}$ and mean post prandial triglycerides $275.65 \pm 48.0 \mathrm{mg} / \mathrm{dl}$ and the difference was statistically significant. Fall in post prandial total cholesterol $(229.72 \pm 53.9 \mathrm{mg} / \mathrm{dl})$ was observed as compared to fasting level $(245.87 \pm 64.5 \mathrm{mg} / \mathrm{dl})$ but the difference observed was not statistically significant. Mean fasting HDL was $42.71 \pm 4.9 \mathrm{mg} / \mathrm{dl}$ while mean post prandial HDL was $40.65 \pm 3.6 \mathrm{mg} / \mathrm{dl}$. It was seen that mean fasting LDL was $156.45 \pm 23.9 \mathrm{mg} / \mathrm{dl}$ and mean post prandial LDL was $145.76 \pm 31.5 \mathrm{mg} / \mathrm{dl}$. It was observed that post prandial VLDL levels $(41.76 \pm 28.55)$ were raised as compared to fasting VLDL levels $(37.90 \pm 17.6)$ but the difference was not statistically significant.

\section{Discussion}

The present study was conducted in the department of medicine of tertiary care institute with the aim to compare the fasting and post prandial lipid profile in patients of IHD. Total 50 cases of IHD were studied and it was observed that total $64 \%$ patients were male and $36 \%$ were female with male: female ratio of $1.73: 1$. While studying various risk factors of IHD in the study population it was observed that tobacco chewing (30\%) was the most common risk factor observed followed by smoking and hypertension (20\%). It was observed that mean fasting sugar level of the study subjects was $85.41 \pm 21.24 \mathrm{mg} / \mathrm{dl}$ while post prandial sugar 
level was $112.65 \pm 24.52 \mathrm{mg} / \mathrm{dl}$. Thus, the patients of CHD had significantly higher levels of post prandial blood glucose as compared to fasting glucose level. Vijay Shankar19 observed $82.1 \pm 15.0 \mathrm{mg} / \mathrm{dl}$ fasting glucose and $114.5 \pm 20.3 \mathrm{mg} / \mathrm{dl}$ post prandial glucose with statistically significant difference. In their research, Jarret RJ ${ }^{[20]}$ and Balkau $\mathrm{B}^{[21]}$ found identical results. TG rich lipoproteins in PP state act adversely on vascular endothelium through increasing superoxide anion radicals or by direct impairment of vascular endothelium by decreasing coronary bioactivity [13, 14, 22-24].

In another study, it was found that atherosclerosis was associated with PP TG levels independently of fasting TG suggesting that lipoprotein characteristics specific to PP state are atherogenic ${ }^{[25]}$. Roche et al. Have shown that severity and length of PP lipemia is positively linked to the pathogenesis and development of CHD. An elevated lipemic response precipitates a number of adverse metabolic events by activating the coagulation factor VII and plasminogen activator inhibitor [26, 27]. Fall in post prandial total cholesterol was observed as compared to fasting level but the difference observed was not statistically significant. Mean fasting $\mathrm{HDL}$ was $42.76 \pm 4.7 \mathrm{mg} / \mathrm{dl}$ while mean post prandial HDL was $40.65 \pm 3.5 \mathrm{mg} / \mathrm{dl}$. It was seen that mean fasting LDL was $156.48 \pm 23.8 \mathrm{mg} / \mathrm{dl}$ and mean post prandial LDL was $145.76 \pm 31.4 \mathrm{mg} / \mathrm{dl}$. It was observed that post prandial VLDL levels were raised as compared to fasting VLDL levels but the difference was not statistically significant. The postprandial VLDL levels followed the same trend as the TG levels. Similarly Ayyappan et al. ${ }^{[28]}$ in their study observed that VLDL had a significant postprandial rise and was considered as a component of postprandial lipemia as well. Boccalondro et al. ${ }^{[29]}$ They observed that people with coronary artery disease have a longer postprandial lipemia than healthy people. Hyperlipidemia is well known to be a risk factor for cardiovascular disease, and fasting lipoprotein measurements are now considered the standard of care when assessing a patient's lipid profile, according to ATP III recommendation guidelines ${ }^{[30]}$. In a clinical setting this creates an inconvenience for patients and providers alike. However, recent studies have raised doubts as to whether fasting lipids should be measured and therefore clinical practice changed.

\section{Conclusion}

Thus we conclude that there was that there was no significant clinical difference between fasting and nonfasting levels of total cholesterol, HDL, and LDL except Triglycerides where TG was raised statistically significant post prandially.

\section{References}

1. Rosenson RS. Hypertriglyceridemia and coronary heart disease risk. Cardiol Rev 1999;7:342-8.

2. Zilversmit DB. Atherogenesis: A postprandial phenomenon. Circulation 1979;60:473-85.

3. Rifai N, Warnick GR. Lipids, lipoproteins, apolipoproteins, and other cardiovascular risk factors. In: Burtis CA, Ashwood ER, Bruns DE, eds. Tietz Textbook of Clinical Chemistry and Molecular Diagnostics. 4th ed. Philadelphia, Pa: Elsevier Saunders 2006, 903-982.
4. Executive summary of the Third Report of the National Cholesterol Education Program (NCEP) Expert Panel on Detection, Evaluation, and Treatment of High Blood Cholesterol in Adults (Adult Treatment Panel III). JAMA 2001;285:2486-2497.

5. De Backer G, Ambrosioni E, Borch-Johnsen K, Brotons $\mathrm{C}$, Cifkova R, Dallongeville $\mathrm{J}$ et al. European guidelines on cardiovascular disease prevention in clinical practice: Third Joint Task Force of European and Other Societies on Cardiovascular Disease Prevention in Clinical Practice. Eur Heart J 2003;24:1601-1610.

6. Cohn JS, McNamara JR, Cohn SD, Ordovas JM, Schaefer EJ. Postprandial plasma lipoprotein changes in human subjects of different ages. J Lipid Res 1988;29:469-479.

7. Schaefer EJ, Audelin MC, McNamara JR, Shah PK, Tayler T, Daly JA et al. Comparison of fasting and postprandial plasma lipoproteins in subjects with and without coronary heart disease. Am J Cardiol 2001;88:1129-1133.

8. Bansal S, Buring JE, Rifai N, Mora S, Sacks FM, Ridker PM. Fasting compared with nonfasting triglycerides and risk of cardiovascular events in women. JAMA 2007;298:309-316.

9. Nordestgaard BG, Benn M, Schnohr P, TybjaergHansen. Nonfasting triglycerides and risk of myocardial infarction, ischemic heart disease, and death in men and women. JAMA 2007;298:299-308.

10. Zilversmit DB. Atherogenesis: A postprandial phenomenon. Circulation 1979;60:473-85.

11. Bae JH, Schwemmer M, Lee IK et al. Postprandial hypertriglyceridemia induced endothelial dysfunction in healthy subjects is independent of lipid oxidation. Int $\mathbf{J}$ Cardiol 2003;87:259-67.

12. Ernst JS, Marie CA, Judith R et al. Comparison of fasting and postprandial plasma lipoproteins in subjects with and without coronary heart disease. Am J Cardiol 2001;88:1129-33.

13. Plotnick GD, Corretti MC, Vogel RA. Effect of antioxidant vitamins on the transient impairment of endothelium dependent brachial artery vasoactivity following a single high fat meal. J Am Med Assoc 1997;278:1682-6.

14. Kugiyama K, Doi H, Motoyama $\mathrm{T}$ et al. Association of remnant lipoprotein levels with impairment of endothelium dependent vasomotor function in human coronary arteries. Circulation 1998;97:2519-26.

15. Orekhov AN, Tertov VV, Mukhin DN. Desialyated low density lipoprotein- naturally occurring modified lipoprotein with atherogenic potency. Atherosclerosis 1991;86:153-61.

16. Gordel T, Castelli WP, Hjortlaud MC. High density lipoprotein as a protective factor against coronary heart disease. The Framingham Study. Am J Med 1977;62:707-14.

17. McGowan MW, Artiss JD, Strandbergh DR. A peroxidase coupled method for the colorimetric determination of serum triglycerides. Clin Chem 1983;29:38-542.

18. Friedewald WT, Levy RI, Fredrickson DS. Estimation of the concentration of low density lipoprotein cholesterol without the use of the preparative ultracentrifuge. Clin Chem 1972;18:499-504. 
19. Vijay Shankar, Harnam Kaur, Kiran Dahiya, Gupta MS. Comparison of Fasting and Postprandial Lipid Profile in Patients of Coronary Heart Disease. Bombay Hospital Journal 2008;50(3):445-49.

20. Jarret RJ. The cardiovascular risk associated with impaired glucose tolerance. Diabet Med 1996;13:15-9.

21. Balkau B, Bertrais S, Ducimetiere P et al. Is there a glycemic threshold for mortality risk? Diabetes Care 1999;22:696-99.

22. Shaikh M, Wootton R, Nordestgaard BG et al. Quantitative studies of transfer in vivo of low density, Sf 12-60 and Sf 60-400 lipoproteins between plasma and arterial intima in humans. Arterioscler Thromb 1991;11:569-77.

23. Patsch JR, Miesenbock G, Hopferwieser $\mathrm{T}$ et al. Relation of triglyceride metabolism and coronary artery disease: studies in the postprandial state. Arterioscler Thromb Vasc Biol 1992;12:1336-45.

24. Bjorkegren J, Boquist S, Samnegard A et al. Accumulation of apolipoprotein $\mathrm{C}-1$ rich and cholesterol rich VLDL remnants during exaggerated postprandial triglyceridemia in normolipidemic patients with coronary artery disease. Circulation 2000;101:22730 .

25. Sharrett AR, Heiss G, Chambless LE et al. Metabolic and lifestyle determinants of postprandial lipemia differ from those of fasting triglycerides. The Atherosclerosis risk in communities (ARIC) study. Arteioscler Thromb Vasc Biol 2001;21:275-81.

26. Roche HM, Gibney MJ. The impact of postprandial lipemia in accelerating atherothrombosis. J Cardiovasc Risk 2000;7:317-24.

27. Karpe F. Postprandial lipoprotein metabolism and atherosclerosis. J Intern Med 1999;246:341-55.

28. Ayyappan S, Kalyananibehra A, Ilanchezhian $\mathrm{T}$. Comparison of post prandial lipid profile at an interval of 2 hours and 4 hours in patients of coronary heart disease. Int J Pharm Sci Res 2017;8(4):1846-49.

29. Boccalandro F, Farias J, Boccalandro C, Vaisman D. Frequency of postprandial lipemia after a first acute coronary event (unstable angina pectoris or non-STsegment elevation acute myocardial infarction) and the effects of atenolol on the lipemia. Am J Cardiol 2002;90(2):153-6.

30. Third Report of the National Cholesterol Education Program (NCEP) Expert Panel on a. Detection, Evaluation, and Treatment of High Blood Cholesterol in Adults (Adult b. Treatment Panel III) final report. Circulation 2002;106(25):3143-421. 